\title{
Verbatim Report of Debate
}

ARRANGED BY THE FELLOWSHIP OF MEDICINE

ON THE MOTION

“THAT OPERATIONS FOR THE REMOVAL OF TONSILS ARE TOO OFTEN PERFORMED WITHOUT ADEQUATE CAUSE."

HELD AT

MANSON HOUSE, PORTLAND PLACE, W.r.

ON

THURSDAY, DECEMBER $7^{\text {th }}$, I933.

SIR StCLAIR THOMSON, M.D., F.R.C.P., F.R.C.S., in the Chair.

Proposers of the Motion:

Mr. Herbert Tilley, f.r.c.s. Dr. J. Alison Glover, o.b.e.

Opposers of the Motion:

Dr. Dan McKenzie, F.R.c.s.

Mr. Archer Ryland, F.R.c.s.

The Chairman: Ladies and gentlemen. First of all I would like to say it is a very great honour for me to have been chosen to take the Chair at this debate. It really looks as if a prayer I had offered up for the last five years was approved, and the prayer was "O Lord, give us a right judgment in all things". I do not think my judgment will be right, but it will be the "rightest" I can give. To have been chosen to hold the ropes in this debate is very flattering to my amour propre.

I shall not detain you by any opening: we will hear much discussion "about it and about". Personally, I have the greatest belief in these discussions, as they help to clear the atmosphere. It was suggested to me just now that I need have no difficulties, because the only duty of a president is to preside, or, as someone said just now, to hold the ropes to see that there is no hitting below the belt, as I am sure there will not be. We should do as adversaries do in Law: Strive mightily but eat and drink like friends.

I will ask Mr. Herbert Tilley to open the discussion.

Mr. Herbert Tilley, F.R.C.s.

Mr. Chairman and Gentlemen,

If it be permitted to do so, I would like to congratulate this Society for arranging a debate which, by the many implications of its title, must be of great practical interest to all members of our profession and irrespective of the type of work in which they are engaged. 
No doubt the subject will be approached from many different angles, but I make bold to say that there will be no dissent from the general statement that, for many of the sub-acute and chronic ailments of children up to the age of puberty and even to adolescence, no medical or surgical treatment has so quickly restored such patients to normal and prolonged good health as has the removal of enlarged and/or diseased tonsils. But, unfortunately, this general conviction has led to an almost automatic assumption that a disproportionate number of such maladies in children, and only less frequently in adults, are due to "septic tonsils" and consequently these often removed "without adequate cause"-or, as I would prefer to express it, "without adequate examination of patients for other possible causes of their symptoms."

This would seem to be the view of those who organised this debate and composed its title, and there can be little doubt that it expresses an opinion which has gained increasing support from the profession during the last ten or fifteen years. Furthermore, most of us must have had evidence that the lay public is becoming more apprehensive in proportion to the number of patients for whom tonsillectomy has failed, not only to cure the symptoms for which that operation was performed, but has sometimes added others to them.

Before embarking on the reasons which have led me to support such opinions, it may be well to ask ourselyes two questions:

(I) What are the functions of the tonsils?

In answering this, we should keep in mind the significant fact that Nature has provided every new-born infant with an almost continuous ring of sub-epithelial lymphoid tissue which extends from the nasopharynx by way of the faucial tonsils to the base of the tongue. Furthermore, it is interesting to remember that in the "solitary" and "Peyer's glands" found in the intestines there are similar deposits of an almost identical tissue and that in each of these situations these lymphoid structures are well developed in the young subject and tend to natural involution as age advances. It may also be added that, with very few exceptions, e.g., the rat, all mammals have more or less well developed tonsils.

With regard to their function, it will suffice to remind you that the careful research work of histologists, bacteriologists, pathologists and clinicians leave little doubt that the lymphoid nodules provide a constant supply of lymphocytes and also phagocytes which destroy noxious organisms which reach the tonsils through the mouth and the nasal air passages. In this warfare it also seems probable that a certain degree of general immunisation is afforded.

If it be argued that this is a view which lacks proof, let us put the question to Nature for surely we may safely abide by her answer.

It is not an uncommon experience to see young patients who a year or so previously have had their tonsils (and adenoids) removed, and to find that during the interval large patches of lymphoid tissue have been deposited on the posterior wall of the pharynx and on its lateral walls, i.e., the so-called "lateral pharyngeal bands". Or, again, that the lower halves of the tonsillar fossæ have become occupied by an upward development of the adjacent lingual tonsils-an appearance which may convey the wrong impression that the original faucial tonsils were not completely removed. (Incidentally, may I suggest that when consulted by such patients who have been operated upon by another surgeon, we should 
not forget that of "Faith, Hope and Charity, the greatest of these is Charity.") Now, when we meet with such conditions does not Nature seem to say, "I placed those structures there for a definite purpose, you removed them, and since I must protect my child, I have replaced them where it has been possible to do so."

Unfortunately, these new deposits often lead to complaints of dryness and soreness of the throat and frequently an irritating cough, symptoms which are sometimes difficult to cure without cauterisation. So here we have an instance of removal of the tonsils followed by symptoms which did not exist before the operation, and they may be so troublesome as to make the last condition of the patient worse than the first.

When such cases have occurred in my own practice, they have always given me the unhappy feeling that my judgment may have been at fault, or, as the title of our debate puts it, an operation had been performed on the tonsils "without adequate cause".

The second question is: "What are the clinical or pathological appearances which render the tonsils a menace to health, or-in common parlance- "What constitutes a "septic tonsil" "?

I will commence my answer by stating what, in my opinion, is not a septic tonsil from the clinical point of view. We know that from a few days after birth to the last day of second childhood it would be possible to detect bacterial flora in the crypts of the tonsils. It is probable that from each member of this audience it would be easy to express some yellowish-white plugs of débris from one or more recesses of his or her tonsils, and the bacteriologist would report that it contains broken down epithelial cells, lymphocytes, leucocytes, fibrinous material, pyogenic and, probably, certain types of pathogenic organisms. These form the usual exudate found in the crypts which tends to be expelled during the act of swallowing while any which remains can be dealt with by the normal defences of the tonsils.

To remove the latter simply because such material can be pressed out of their crypts is-it seems to me-no more justifiable than it would be if a surgeon, when consulted by a patient with some abdominal discomfort, applied drastic treatment to the rectum because he found some fæcal remnants in it.

And yet I would ask, have not our professional experiences during recent years convinced us that many tonsils have been removed because a small plug, such as I have described, could be made to appear from the recesses in the upper poles of their capsules? If this be so, has not tonsillectomy often been performed "without adequate cause"?

What, then, do we imply by a "chronic septic tonsil", which may be a menace to the individual.

(I) From the histo-pathological aspect, we may regard it as one in which the natural protective barriers have broken down so that pus-producing and pathogenic organisms, with their toxins have entered the lymphoid follicles and thus found their way by the lymphatics of the tonsils into the general circulation. As a result of this invasion of the tonsil we may expect to find various signs and degrees of inflammation in the tonsils coupled with a history of recurrent attacks of acute tonsillitis and/or distal symptoms suggesting a mild general toxæmia which is often associated with one or more local manifestations, e.g., myositis, 
neuritis, types of infective arthritis, symptoms suggestive of cardiac infection, certain skin lesions and an increasing number of other affections of which the latest and perhaps the most striking are some mental diseases to which William Hunter has applied the term "septic psychoses".

(2) From the clinical point of view we cannot give a more concise answer than Hajek's dictum, "The most certain proof of a chronic tonsillitis is, always, the occurrence of repeated acute attacks."

But if such repetitions were few and far between, and in the meantime other signs and subacute symptoms of focal sepsis were in evidence, the tonsils might equally be condemned on the following grounds: tonsil ;

(a) The escape of liquid pus from the crypts when pressure is applied to the

(b) An enlarged tonsillar gland behind the corresponding angle of the jaw, possibly varying in size from time to time and sometimes painful on pressure. The neighbouring anterior cervical glands may be in a like condition;

(c) A purplish-red tinge limited to the anterior faucial pillar and in marked contrast with the surrounding normal mucous membranes. This condition is generally indicative of streptococcic infection of the underlying tonsil and frequently associated with distal arthritic complications:

(d) An abnormal preponderance of leucocytes in material taken from the crypts of the tonsils. Such excessive leucocytosis is frequently accompanied by general hyperæmia of the pharyngeal and palatal mucous membranes. Incidentally one may mention that the size of a tonsil is no criterion of the nature or degree of sepsis within it. A large tonsil may be far more harmless than another which is small, retracted and fibrous.

In either case, once it has been established that chronic infection is present, the tonsil should be removed for only by such treatment can the local symptoms be cured. However unanimous we may be on this point, many differences of opinion exist among the most careful observers as to the relationship between chronic tonsillar sepsis and its possible distal manifestations.

It is probable that most of us could record some striking successes after removing obviously septic tonsils associated with chronic neuritis, infective arthritis, disordered action of the heart, iritis, rebellious skin diseases and so forth, but has not the happy recollection of them been sadly diluted by the memory of failures to cure, or even to relieve what appeared to be identical conditions in other patients? Where and what, could have been the missing links which made so many gaps in the chain of success?

In our perplexity to account for such diverse results, we have not been much helped by the literature on the subject, e.g., Lillie \& Lyons claim 79 per cent. of improvements after tonsillectomy for myositis and arthritis no matter what the condition of the tonsils may be.

Poynton, in his recent treatise on Rheumatism, says " even the greatest enthusiasts cannot pretend that the operation is either a certain cure for rheumatism or an infallible prophylactic measure and they will have to confess that in many instances tonsillectomy has no influence whatever on the course of the disease" I can confirm this statement because for many years several of the cases on which 
he has based his opinion were operated on by me after consultation when I was his colleague in University College Hospital.

Similar failures to cure or relieve conditions presumed to be due to septic tonsils are to be found in Kaiser's report on 2,200 tonsillectomised children whose histories were followed up for Io years.

If such failures may be regarded as instances in which the operation was performed without adequate examination of the patient, surely the essential cause of the symptoms must have been overlooked.

If any proof of this contention be necessary, I would refer you to the work of Dr. Ralph Pemberton, published in the Trans. Amer. Laryngolog. Asscn. of I923. During the latter part of the War and for some time afterwards, he was a medical officer in charge of a large camp of soldiers, and with his colleagues made an intensive study of 400 cases of arthritis, particularly in relation to focal sepsis. After analysing his statistics he says, "But at all events nearly one half got well in the presence of a definite surgical focus. Tonsillectomy was one of the most frequent procedures carried out in the way of removing focal infection, and about I6 per cent. improved or got well as the result of surgical foci in the seven months that we had opportunity to observe these men. So that in the last analysis, looking at the matter dispassionately and desiring simply to get facts, the outstanding deduction is that an overwhelming proportion got well in the presence of demonstrable surgical infection and relatively few got well as a result of removing foci."

He then goes on to show that where failure to improve, or to cure, followed surgical removal of septic foci, it was often found to be due to faulty metabolism as proved by a lowered sugar tolerance, defective blood oxygenation and evidences of "a more or less permanent dislocation of some physiological functions."

Fletcher (Toronto), has since corroborated Pemberton's work "In a series of I5o cases he found that 40 per cent. of unselected cases showed improvement from the measures (directed to defective metabolism) without regard to whether or no they presented focal infections."

After reading the papers referred to, these investigations seem to have amply proved, at least, one aspect of the question, namely, that even if an obvious focus of infection be removed, whether centred in the teeth, tonsils, or nasal sinuses, the operation will have no effect on a large number of cases while in others it will be only one of the links in a chain of further and more comprehensive treatment.

How then are we to act when confronted by a patient with chronic infection of the tonsils associated with some distal manifestation which, we might hope to cure by tonsillectomy? Surely, it reasonably would be our duty to lay the pros. and cons. before the patient and let him share in the onus of decision with regard to operative intervention. If he decides to "think it over" it would be well in the meantime to hand him over to a physician for the type of examination such as Dr. Pemberton so skilfully employed for some of his patients. By so doing we may find that we are not in the category of those who operate "without adequate cause."

In conclusion, it may be opportune to draw attention to the significance of certain general and local factors which, in my own experience, may cause enlargement and/or inflammation of the tonsils. If such conditions were more freely recognised and appropriately treated there can be little doubt that many contemplated tonsillectomies would prove to be unnecessary. 
(I) The presence of a deficiency disease such as rickets which is so commonly associated with enlarged tonsils and adenoids. The same holds good for children who are brought up on diets containing an:excess of carbohydrates and fats but deficient in the essential Vitamin A.

(2) There is no need for always removing slightly enlarged tonsils when the patient's symptoms are typical of adenoid obstruction. The removal of these growths will frequently and quickly be followed by a return of the tonsils to their normal conditions.

(3) Dental sepsis is a frequent source of tonsillar congestion in children and sometimes in adults, and, if it received suitable treatment, many tonsil operations would be unnecessary.

(4) Nasal sinus infection. Many enlarged tonsils-often accompanied by adenoids-are the result of an infection of the nasal air-sinuses and particularly of the antrum. This condition is far more common in young children than is yet appreciated even by throat and ear surgeons. It is the explanation of a large proportion of those cases in which nasal discharge, cough, and bouts of mild pyrexia continue after the removal of tonsils and adenoids. Experience has amply proved that if the nasal sepsis be removed in the first place, no further operation on the nasopharynx and throat will be necessary. In making this statement, I am well aware that the sinus infection may be a result of sepsis derived from the tonsils and adenoids, and by the removal of these obstructive elements the discharge from the air-cells will quickly and spontaneously disappear, but, even so, there will be a considerable residue of cases which, from their history and the result of treatment primarily directed to an infected antrum, prove this to have been the initial cause of the tonsil-adenoid infection.

A convincing paper will shortly be published by one of our junior colleagues which should go far to substantiate this view and if it does do so, it will have the effect of replacing a number of tonsillectomies by the comparatively simpler operation of antral lavage.

(5) We are all familiar-at any rate the seniors amongst us-with the nasopharyngeal symptoms which so frequently accompany the advent of puberty especially in boys, e.g., nasal stuffiness, occasional epistaxis, fullness of the tonsils, each or all of them frequently accompanied by listlessness and an altered behaviour which alarm their parents. It is difficult to speak in polite language of those who would employ surgery for such a temporary and natural physiological disturbance. At the least, they are of those who operate "without adequate cause".

These, ladies and gentlemen, are a few personal reflections and scattered thoughts on the subject which is before us and if, in any small way, they support the title of this debate and provoke a useful discussion, I shall have my most abundant and satisfactory reward.

One final word, and that a story told by Lord Riddell in his charming book entitled "Looking Round." He was discussing with the late President of the United States, Mr. Woodrow Wilson, some of the big issues involved by, and prior to, the signing of the Treaty of Versailles and anent one of these, the President in speaking of himself said he had "a single-track mind with no sidings". Was it, I wonder if "by that sin the Angels fell" - no less than did some of the politicians? 
Is it not also possible, that "specialism" has led us unconsciously to the "single track" type of mind? If so, may we not become a greater danger even than the politicians-because we have to guard the general health of the community and combat the hazards of individual lives? Compared with our law-givers, we are members of a much older and perhaps nobler profession and only so long as we travel on broad gauge lines and explore their many junctions can we advance the Science and Art of our Craft.

If with a wide vision we strive towards that ideal, we may, at least, hope to lessen the apprehension "That tonsils are too frequently operated on without adequate cause."

\section{Dr. J. Alison Glover, o.B.E.}

I rise to second this motion which Mr. Herbert Tilley has so cogently moved. First, I would emphasise that tonsillectomy is often performed for perfectly adequate causes, and that in such cases it is an entirely justifiable and beneficient operation. I hold no brief for the retention of diseased or really obstructive tonsils, and I have no wish to cast doubt upon the high value of the operation in cases in which there is sure evidence of toxic or obstructive damage.

Why then, do I second a motion that it is " too often performed without adequate cause" ? Let me briefly review the history, the geography, the age and social grouping of the incidence and then glance at the relative frequency of the causes for which the operation is performed and the statistical evidence that the end-results hoped for are attained.

First, as to HISTORY : In I885 that great physician and astute observer, Goodhart, said of tonsillectomy, "It is comparatively seldom that an operation is necessary, and fortunately so, for parents manifest great repugnance to it. Children generally grow out of it and at fourteen or fifteen years of age the condition ceases to be a disease of any importance". Now we see that, despite a solemn warning from the Chief Medical Officer of the Board of Education in I923 as to excessive operation, in the eight subsequent years (ending I930) the operation rate increased 250 per cent. for London, 225 per cent. for English and Welsh elementary school children. In my youth $I$ went to a preparatory school of $5^{\circ}$ boys and then to a public school of 650 boys. I, a doctor's son and destined for medicine, do not remember a single boy at either school who had had his tonsils removed. School epidemics were, if anything, less frequent. Nor does a study of old photographs reveal any greater prevalence of mouth-breathing or adenoidal facies. Now I am authoritatively informed that, in one of the chief public schools 75 per cent. of the boys have had their tonsils removed before entry, and that this percentage is increasing 2 per cent. per year. If this increase be maintained, in I2 years there will not be a whole tonsil (though there may be a fair number of remnants) in the school. The population of about II,O0o healthy pupils in wellto-do boarding public schools which the School Epidemics Committee of the Medical Research Council has under observation, had 55 per cent. boys and 48 per cent. girls tonsillectomised in I932, the percentage showing an increase of about 2 per cent. per annum. In the Lent term of I932, one wealthy and celebrated boarding school with some 500 boys had 84 per cent. of its boy population tonsillectomised, a 20 per cent. increase in 2 years.

Still looking at the history, let me speak for a moment of adenoids, a subject inextricably associated with tonsillectomy. In I868, Wilhem Meyer visited Londop. 
and first described adenoids to the Medico-Chirurgical Society. He examined 700 London elementary school children and found that r.8 per cent. suffered from adenoids. In I930, 62 years later, at an examination by an aurist of $1,36 \mathrm{I}$ "representative" London elementary school children, I2.8 per cent. have already had their adenoids removed, and of the remainder adenoids were present in 54.9 per cent. with or without tonsillar enlargement, and I5 per cent. had enlarged or septic tonsils. Including those whose adenoids had already been removed, adenoids were or had been present in 67.7 per cent. In an inquiry, I93I, into the relative incidence of adenoids and enlarged tonsils in "catarrhal" and "unselected" pre-school children of 3-4 years, no difference was found, roughly 60 per cent. of the children in each group having the combination.

Such statements as the foregoing or as this -73 per cent. of the children admitted to the Nursery School in a Midland County Borough had enlarged tonsils-suggest very strongly that much of the enlargement nowadays considered morbid is merely physiological.

Let us turn from history to geography. Dr. Gustav Seiffert, the medical officer of health for Munich, told me some I8 months ago that in that city not more than 0.5 per cent. of secondary school children have been tonsillectomised, whilst in the country districts around, hardly any children have had the operation. In the country districts of south-eastern Missouri only 2 per cent. of school children are tonsillectomised, although rates in America are generally very high.

In England wide variation is seen in the proportion which the number of tonsillectomies performed on elementary school children bears to the average school attendance in the respective areas. A certain geographical distribution we might expect and understand. But instead of any reasonable variation, we find such examples as these, that one town has a ratio eight times as high as a very similar town five miles away: that a prosperous urban district in the neighbourhood of London has a ratio six times as high as its immediate neighbour, a rather less prosperous but very similar and efficiently administered urban district: that one rural county has a ratio of four or five times that of its immediate neighbour, a similarly rural county. This eratic variation of geographical distribution of the incidence of the operation, which, for the most part, has no relation to the relative health or efficiency of the administration of the health services, must give rise to suspicions that the incidence of the operation is too often determined by factors other than adequate cause.

Now let us look at the age grouping of the incidence. There has been, as you know, a marked trend, partly professional partly parental, to have the operation performed at ever earlier ages so that the peak of the incidence is now at 6 years. This period of the child's life is the threshold of great changes in the oral cavity; and that the peak of operations should occur at a period when physiological enlargement is probably at its height and when the child is first acquiring its immunity to school infection, suggests that some of these operations are for enlargement which is physiological. rather than morbid, or temporary, recoverable and even possibly beneficial from the point of view of immunity.

The causes for which tonsillectomy is performed are very various and exceedingly difficult to classify. Dr. Ash (C.M.O. Derbyshire), in I,69I elementary school children found that 20 per cent. were operated on for frequent sore throats and tonsillitis; I2 per cent. for frequent colds; I2 per cent. for chest conditions; 
II per cent. for enlarged turbinates (Io per cent. of these having associated deviated nasal septum); II per cent. for earache and obstructive deafness; 4 per cent. for tubal catarrh ; 6 per cent. had otitis media ; 6 per cent. enlarged cervical glands ; 4 per cent. had rheumatic conditions ; 9 per cent. "systematic and general conditions"; 3 per cent. eye condition; 4 per cent. "reflex conditions".

Thus, the indications in about 44 per cent. of the operations were frequent infections of throat, nose, or chest; in 20 per cent. deafness or ear trouble, and in 4 per cent. rheumatism-in all about two-thirds of the cases.

This is as good a classification as we can get, but you will see no reference in it to simple enlargement, which though really a cause for many operations is always cloaked by other reasons.

Let us go through these causes and see what we may hope for. I2 per cent. are for chest conditions, yet Kaiser (an observer by no means prejudiced against the operation) found that the figures for bronchitis during both his three-year and ten-year periods were twice as bad for the tonsillectomised children as for the non-tonsillectomised children; his figures for pneumonia were also definitely worse. These results seem significant, for his control children had exhibited equal indications for tonsillectomy as his tonsillectomised children before operation, thus eliminating any error due to the fact that child who is often ill (particularly with respiratory infections) is more likely to be operated on.

With regard to frequent colds, which form 20 per cent. of Ash's series, Kaiser found that tonsillectomy offers no sure protection against colds but effects some reduction in their incidence, especially in the earlier school years. Smiley, dealing with students of Yale University, said that the removal of nasal obstructions and diseased tonsils in more than half of those having four or more colds in a year did not result in a reduction, whilst Forsythe, in 537 students of the University of Michigan, found that the tonsillectomised had 40 per cent. more acute respiratory infections than the non-tonsillectomised. In this country Bradley has found that nasopharyngitis occurs irrespective of the presence or absence of the tonsil, and that the operation is of no appreciable value in the prevention of epidemic nasopharyngeal infections.

The observations made for the School epidemic committee by Dr. Wilson and myself on II,OOo public school boys and girls, as far as they have gone, confirm Bradley's observation.

Severe and repeated tonsillitis is perhaps one of the surest indications for tonsillectomy, but we found no significant difference in incidence between tonsillectomised and non-tonsillectomised in the incidence of respiratory infections, nasopharyngitis, or otitis media. If there were any advantage, it lay with the non-tonsillectomised. Nor can the argument be successfully advanced that the high rate of tonsillectomy had put the weak, those most likely to be infected, i.e., the tonsillectomised, on a level with the strong, for in these public schools the weak and the strong are equally and indifferently tonsillectomised. Taking only boys in the first football teams of I8 great public schools, we found 55 per cent. tonsillectomised, exactly the same ratio as the total boy population. One celebrated school had 80 per cent. of its first XV tonsillectomised.

A high tonsillectomy rate does not increase the herd immunity of a preparatory or public school to nasopharyngitis and otitis; if anything, it appears to lower it. 
I should like to have dealt more fully with this question of end-results, but I must refer you to the paper by Dr. Wilson* and myself for details especially with reference to otitis, rheumatism, and malnutrition. I would ask you to consider carefully the following points:-

(I) the immense and rapid increase in the numbers of tonsillectomies annually performed ;

(2) more than half the most carefully nurtured children in this country are now subjected to it, whereas 40 years ago none of their parents underwent the operation ;

(3) whilst the incidence of tonsillitis is at least as high amongst the poor as amongst the well-to-do, the children of the latter have an incidence of tonsillectomy at least four times as high;

(4) with the single exception of diphtheria, the incidence of the ordinary infectious diseases is unaffected by tonsillectomy; that while the incidence of recurrent sore throats is perhaps somewhat diminished, that of frequent colds is unaltered, or perhaps slightly increased;

(5) the incidence of otitis and mastoid disease is the same, or perhaps slightly increased upon the tonsillectomised, while their liability to bronchitis and pneumonia is also probably slightly increased;

(6) the evidence with regard to the effect of tonsillectomy on acute rheumatism, chorea, and carditis is conflicting, but there is no sufficient case for the routine removal of apparently healthy tonsils in a rheumatic or potentially rheumatic child, simply as a measure of prophylaxis against acute rheumatism. Removal should only be undertaken if there is some specific indication;

(7) whilst there is no reason to doubt the high value of the operation in cases in which there is sure evidence of toxic or obstructive damage, there is in the facts enumerated clear evidence that the operation is too often performed without adequate cause, without sufficient regard to the possibilities of purely temporary physiological and immunological enlargement, and to the tendency to spontaneous involution. As a prophylactic ritual the operation is useless, and a large proportion of tonsillectomies now done in children appears to be unnecessary, to involve some risk, and to give little or no return.

*Brit. Med. Journal, 1932, ii. Sept. 10, p.506.

\section{DR. DAN McKenZIE, F.R.C.S.}

I beg to move an amendment to the motion before us:

"That this Meeting, while deprecating ill-regulated operating, affirms its confidence in the operative removal of tonsils and adenoids as a lifesaving and health-giving operation."

In the second place I wish to move a motion, at the end of the proceedings, and it is in these terms:

"That this Meeting appeals to the Medical Research Council to institute an investigation into the causation of the hypertrophy of tonsils and adenoids, with a view to its prevention." 
To the motion as it stands upon the Agenda paper no one can properly object, since, if tonsillectomy is ever performed "without adequate cause" it is, ipso facto "too often" thus performed!

But when this innocuous, this pious resolution is made the cover for an attack upon the whole operative treatment of enlarged tonsils and adenoids in children, then some of us will feel like protesting, and protesting vehemently. For while we yield to none in our demand that every case should be handled for what it is-something unique, nevertheless we find it hard to believe that the mass tonsil-adenoid operating that goes on in Britain is unnecessary and therefore unjustifiable. If there is too much operating in some quarters, there is too little operating in others. If you condemn the one, you must not condone the other.

The fact is, that as justification for mass operating we can point to a mass disease, a real endemic. Consider the range, variety, and multiplicity of the tonsil-adenoid symptom-complexes: frequent coryzas; deafness; suppuration of the middle ear with all its dangers; rhinitis and nasal sinusitis; epistaxis; tonsillitis and the rheumatisms; croup; bronchitis; mal-development of the skeleton; mental dullness that you will see disappearing in the first 24 hours after the operation; to say nothing of the less obvious effects of throat sepsis such as acute osteomyelitis of the long bones; endocarditis and valvular disease of the heart; and certain forms of nephritis.

These many maladies are, of course, not always due to tonsils and adenoids, but our point is, that if any one of them appears in a child who is the subject of enlarged tonsils and adenoids, or adenoids alone, our first duty surely is to remove the most probable cause, namely the tonsils and adenoids. For it is an operation devoid of risk, and it will generally cure the disease.

That it will not invariably do so is true. But is there any method of treatment in medicine that is invariably successful?

At this point we turn to the statistical evidence that has been led to prove the futility, if not the harmfulness of these operations in the mass. We have been shown, in statistical collections and analyses, benefit so seldom following the tonsil-adenoid operation, that, ignoring our own experience and assuming the figures to be reliable, there is no escape from the conclusion that the operation is to a great extent a failure.

But are the figures reliable? I say they are not. I say they are so unreliable that the conclusions based upon them are totally misleading. Consider the following points. The patients are said to have had "tonsillectomy" performed; yet 5 per cent of them have had "tonsillitis" since the operation! We therefore ask: were the tonsils completely removed? To that question there is no reply. We also ask: were not adenoids alone removed in some of the cases? And to that question there is no reply. We also ask: was the operation always efficiently performed. And to that question there is no reply. We also ask: was a recurrence of adenoids after the operation excluded by an examination of the patients. And to that question there is no reply.

That is to say, no one knows whether the tonsils and adenoids were completely and permanently removed or not. All indeed that can be said is, that those patients had, at some time or another, some kind of operation on their throat. 
Yet it is from such light and flimsy data that we are asked to reject what is the general experience of all skilled operators, namely, that the operation permanently cures the symptoms in the great majority of cases. I am ignoring the unskilled operator and also the "anti-everything crank".

Now, in addition to the argument drawn from those statistics, there is another plea put forward by decriers of the operation, namely, that, as enlargement of tonsils and adenoids is an hypertrophy of lymphoid tissue, it is therefore a vital necessity and should not be interfered with. I challenge that view.

The argument tacitly but none the less fundamentally assumes that we know the nature and origin of this lymphoid hypertrophy, whereas it is notorious that we do not. True, the hypertrophy may conceivably be physiological, and, so to speak, compensatory, resembling the enlarged thyroid of endemic goitre, which, as long ago as I898, I showed to be in its inception a simple physiological overgrowth. But, just as the thyroid hypertrophy is accompanied and followed by secondary changes which are definitely pathological, so the lymphoid hypertrophy of Waldeyer's ring is accompanied and followed by changes, in this case septic, that are pathological, and are the fount and origin of the multitudinous maladies we have already enumerated. For that reason we may say: an enlarged tonsil is a septic tonsil; and hypertrophied adenoids are septic adenoids.

Again, nothing even remotely resembling a constitutional deficiency disease such as myxœdema, ever follows complete eradication of tonsils and adenoids.

The physiological argument begins to look rather bedraggled and like a scarecrow, does it not?

Now I am going to make a claim of my own. I can myself remember the generations of children before adenoids were known. I remember the discharging ears and the deafness; I remember the dirty noses and the thick, excoriated upper lips; I remember the "scrofulous" glands in the neck; I remember the vacant, stupid faces; I remember the dacryocystitis, weeping pus. My companions I have seen dying in middle life from heart-disease contracted in childhood after tonsillitis .... Then I turn and look at the young men and maidens of to-day, clean of health and stature, and I see the transformation of a race through the influence of a simple operation!

For all of those reasons I ask you to accept our amendment; "that this Meeting, while it deprecates ill-regulated operating, affirms its confidence in the operative "removal of tonsils and adenoids as a life-saving and health-giving operation."

\section{Mr. ARCher Ryland, F.R.C.S.}

I have the honour to support Dr. Dan McKenzie in opposition to the motion which is before us.

May I say at the outset that those of us who oppose this motion do not claim, and I think are far from believing, that removal of tonsils on the extensive scale still necessary, or indeed on any scale, is to be the final and ultimate solution, of the problem of disease in these glands.

I think our ultimate practice will be far different. That it will be almost entirely preventive. And here I venture to say, is as great a field for preventive notions and ideas, as any in medicine. 
"Shut your mouth and save your life," said George Catlin, the once celebrated authority on the North American Indian. Or if that be not wholly true-if that be too good to be true- we can say, I think, with all confidence: "Shut your mouth and save your tonsils."

But you cannot shut your mouth unless your nose is clear. So that lying at the heart of the problem of tonsil disease and its prevention, is this question of a clear, clean, and healthy nasal airway, together with a healthy turbinal function. Given that condition for the nose, it may be said, that tonsils are, humanly speaking, safe.

The truth probably is that nasal obstruction, and its sequel tonsil disease, are related far more closely than is commonly allowed, to the tyranny of clothes, to the absence of light, to the lack of cutaneous friction and ventilation, and to the lack of that careful treatment of the skin as a whole, so indispensable for normal healthy nasal respiration. But prevention, along whatever lines, is, after all, a problem for solution in the future.

At the present time, by far the most satisfactory method of treatment for established disease in tonsils and adenoids is complete removal, and this, before any extension of disease, local or remote, has time to become manifest.

For the present (to return to the words of the motion), is it true, that the operation for removal of tonsils and adenoids is performed too often? Had this question been asked 20 years ago, fifteen years ago, or even ten years ago, I think the answer would have to have been in the affirmative.

In the last 20 years at my own Hospital, and in the practice of other Hospitals, where I have been able to make enquiries, the number of these cases has very considerably decreased (figures shown). Not only that, but together with this decrease in numbers actually coming to operation, it must be remembered, that there has been a steady improvement both in operative technique, and in anæsthetic skill and appliances, together with a truer realisation of the after care and attention which these patients need. Most of us, now I think, who are in charge of clinics admit all cases as in-patients to the Hospital.

The position is, I think, that whereas in the past, very many operations were performed, somewhat hurriedly, and I am ready to admit, somewhat indiscriminately, now far fewer are performed, but they are carried out with greater skill, greater safety, and with better results.

Then again, the displacement of the guillotine in large measure, in favour of gentle and precise dissection, the introduction of the Davis Boyle gag, the use of suction, the practice of securing vessels and hæmostasis on the table, the elimination of all "tip and run" methods of the past; all these things have conspired to make this operation a.far better and more efficient proceeding than it used to be, and have gone far to justify its present frequency of performance.

Of course, every operation is performed too often, if not performed with all skill and thoroughness.

I have been in the habit of saying that the worst result I ever see in tonsil surgery, is the complete removal of the uvula, the two tonsils remaining more or less intact. 
But apart from mishaps and misfortunes which sometimes will, and over a long enough series of cases, must occur, how often, it may be asked, has any of us heard a regret expressed that the tonsils in any given case were removed. I think such a statement has been very infrequent.

On the other hand, in many a case, a regret that tonsils and adenoids had not been removed years ago, is of somewhat common occurrence.

Now following a skilful removal, there is no disability. The disability lies rather in waiting for unhealthy tonsils to produce their pernicious effects. Are we to wait for the time honoured indications of the text book which too often like an obsolete law, lag behind public opinion? Are we to wait until tonsils grow so large that they interfere with respiration, or with speech, until cervical lymphatic glands have become diseased, or invaded with tubercle, until systemic infections are established, or until middle ears are infected and suppurating. If so, it will many times become our fate, to face the responsibility of imprudent and unwise delay.

Now it has been stated (in favour of this motion) that the incidence of middle ear infection, and mastoid disease is probably the same, or indeed may be somewhat higher in those children who have been submitted to this operation. In other words, the removal of tonsils and adenoids; as regards the ears of children, conveys no benefit, and provides no measure of safeguard for the future.

I submit, that the only possible reply to this is, that experience shows it to be quite untrue.

Let those of us who have had a long series of years in dealing with these cases, simply consult the record of their own experience. Can we truly say that this is so? We cannot say it. On the contrary, we are bound to affirmwith every desire to be moderate-with every desire to be fair, with every desire to make reasonable concession, and to admit occasional failure, that this operation as regards the health of the middle ear and mastoid in children, has been highly benificent in its effect and has done good throughout the world, beyond all calculation and estimate. I appeal to all aurists and laryngologists, to all general practitioners, to all who have at heart the care and health of children, that the general uniformity of experience in this respect, is a fact which cannot be seriously assailed, or overthrown by statistics, however brought forward, or by figures, however assembled.

Again it has been objected that this operation should not be carried out, until it is seen to be, in the terms of that misleading and rather fatuous phrase, "absolutely necessary".

"Absolutely necessary" in this relation may easily come to mean "absolutely too late", "absolutely too long delayed". After all, there are few things in this life that are "absolutely necessary", and our action here, as elsewhere in life, is to be determined not by an absolute condition, but by the free selection of a proper course, at the right time, looking to all relevant matters, and a course which prudence, wisdom and experience, show to be the right and wise course.

Finally, with regard to the acute specific fevers, scarlet fever, measles, whooping-cough and the others. We do not claim immunity, and what authority ever has claimed immunity here, as the result of tonsillectomy. We do not claim that, and we do not claim immunity from motor car accidents, and drownings at sea. 
One last word; if Sir James Goodhart spoke the truth, and if what he said 50 years ago, is still the truth, if we accept all the figures brought forward by Dr. Glover, then there is no alternative. We have then got to look upon this operation as one of the most futile, one of the most fatuous, if not one of the most disastrous of operations ever introduced by the science and art of surgery. But we know that is not so, and in urging you to vote on the right side of this question, I very cordially support the proposal brought forward by Dr. Dan McKenzie . "That while deprecating ill-regulated operating, this Meeting affirms its confidence in the operation for the removal of tonsils and adenoids in children, as a life-saving, and health-giving operation."

The Chairman: At whatever conclusion we arrive-if we do arrive at oneI am sure you will all agree that we are greatly indebted to the openers for the clarity, the quality and the vigour of their assaults; they have once again proved each other orthodox by Apostolic blows and knocks. And we know, as Sydney Smith said, that "Orthodoxy is my doxy, and heterodoxy is the other fellow's doxy". We have had distinguished oto-laryngologists; and I think you will agree with me if I ask someone from another side of practice to address us it will be well, as we have the great pleasure and honour of welcoming here this evening the President of the Royal College of Physicians. I ask Lord Dawson of Penn to speak.

The Right Hon. Lord Dawson of Penn, P.R.C.P.: Mr. President, ladies and gentlemen, I came here this evening, mainly, to be informed, and I have not been disappointed. I have seldom listened to a debate on a higher level and with more entertainment. In the short time at my disposal, and owing to the fact that I am an observer-I hope, an impartial observer-in these matters, I can only hope to touch on one or two detached questions.

I take it it is common ground that enlarged and mechanically obstructing tonsils, and demonstrably diseased and infected, should be removed; they are not worth further comment, I think. But when one comes to the tonsil as a focus of infection or of sepsis, then, I think our difficulties begin. It cannot be denied that you do, from time to time, see cases where you get an almost dramatic improvement, whether it be of rheumatism or of some other general condition, from removal of tonsils. So demonstrable is this that there must be something in it in certain cases. The difficulty arises in deciding whether, in any given case, the tonsil is the guilty party. We all know that Mann, of the Mayo Clinic, tried to clear that up, and he thought he had found a means whereby he could say, in a given case, that a certain focus of infection was guilty. He was disappointed, and we were equally disappointed at these experiments coming to nought. My difficulty, and I am sure it is the difficulty of many of us, is with the tonsil which is moderately enlarged, which does exude something, and which has been shown to be a common condition in even healthy throats; how can we be satisfied that it is the cause of the patient's trouble? I am referring to cases where the tonsil does not, in virtue of its own local condition, lead one to advise tonsillectomy. In our search for focal sepsis we must remember that the number of places in which we can properly search for sepsis is limited. Sometimes the appendix, sometimes the gall bladder may be the focus. We cannot investigate those, but we can investigate, with great ease, the teeth and the tonsils. In fact, we look at them so often that we are apt to acquire an unconscious bias and to juidge them too critically. The difficulty I feel is lest I may advise tonsillectomy too readily. I will give you a reason which probably all my laryngological friends will dissent from. 
No one can guarantee that tonsillectomy, however well done, will not be followed by some functional impairment of the palate. That simply illustrates the fact that there is no operation with which I am acquainted in which you can guarantee a IOo per cent. efficiency result. I am constantly being impressed with the beauty of structure of the palate; it is one of the finest balanced structures in the body: its perfect symmetry, its graceful movements, the way it is attached by its pillars, and the way in which it swings back, as seen well in the case of singers, and comes into contact with the posterior wall of the pharynx will enable you to realise that anything which interferes with that perfect play is something to be avoided, if it is at all possible.

If we take a dissection of the tonsils, however well done, there are certain inherent difficulties in the operation. One is, that you have to leave a rather deep granulating surface in close relation to the pillars; you must leave a surface which has not only length and breadth, but also depth, and therefore is in the nature of a hole, a hole that it horrifies me to look at. It is impossible to say that in the healing up of these holes there will not be some fibrosis. You cannot get cure without it. And it is impossible to say that you will get an equal amount of fibrosis on the two sides, nor can you say how much fibrosis you will get in the case of any individual patient. I am not talking of gross disturbances, I am careful to say some functional impairment. It is extraordinary the number of times I look into a throat, and as I look I see a slight pallor of that part of the palate which is near the operated tonsil. I see the adjacent part of the pillar pale, and obviously a little fibrotic, and the palate has lost some of its flexibility, it has become starched ; and when you ask your patient to say "ah", the palate does not swing back with the grace one is accustomed to see, and it does not come into perfect contact with the posterior wall of the pharynx, nor is it exactly symmetrical.

One step further-and I am talking of minor things-it is not very infrequent to see a small fan-shaped scar just where the base of the pillar of the fauces is. I often joke my friends on this matter, and they tell me the thing was not well done. The reason is that those results are inseparable from the operation. It may be that the tendency to fibrosis varies; some individuals have a greater tendency to fibrosis in all parts of the body than others have. That would not prevent my advising that tonsils be taken out; all I say is it makes imperative that you must have good cause for doing it. I cannot believe, when the figures of this operation in England have gone up a quarter of a million compared with the figures a few years ago, that all those increased operations are necessary.

I wish to be constructive. May I revert to my "starched palate" ? In that, you do not get perfect apposition, you get streaks, and you are apt to get an ensuing tendency to post-nasal catarrh, which as the years pass may get worse. Thereby there is a tendency to bronchial catarrh which otherwise would not have happened. That is not an argument against operation, but an argument for great discrimination in doing it. These are observations of a mere physician.

When looking at these tonsils I have often said to myself, "Are we sure that when there is infection of this part of the body, that the tonsil is the primary focus? Is not the reverse often the case?" Is it not true that it is often the nasopharynx and the sinuses which are the source of the trouble? When Nature made a beautiful thing of the human face, Nature entirely forgot to provide proper drainage; I suppose there is no place where drainage is worse than in 
that part, and it is easy, in the atmosphere in which we live, to get those sinuses infected. If they were examined by a better technique, and if there were more people acquainted with that technique-there are few people who are-matters would be better. That is the difficulty in the present system of taking out tonsils; only a few know the best technique, and the surgeon plunges straight at the tonsil without examining the nasal sinuses. I have worked out some cases, and I have been impressed with the frequency with which there may be sub-acute infection of those sinuses; and if they were washed out with skilled hands it would obviate the tonsil.being removed. I have noticed, in many instances, the tonsil go down in these circumstances. I put that suggestion to the meeting for my specialist friends to criticise.

A very apt remark was made tonight about "single-track minds". That is a danger that we are all exposed to now. It is very difficult to cover all the ground. But the Public Health service of this country is responsible for having developed an entirely new class of single-track mind, namely, this large number of people who take out tonsils in connection with school services. These practitioners in question have not had a chance, they are scattered in country districts, they do not rub shoulders with members of hospital staffs. They attain to a reputation for taking out tonsils, and most of them have had no adequate instruction in the technique of the nose, and their work is done at great speed. It almost becomes a Robot method of dealing with them. People say, "They do not take out the tonsils completely," to which I ejaculate, "Thank God" (Laughter). For this reason: that if you dissect a tonsil out well, it is to the benefit of the patient if you do it well. If you do it badly you will do more harm to your patient than if you did it with the guillotine.

This is an occasion to draw attention to the fact that this Public Service method of separating diagnosis from treatment, from the general trend of medical knowledge, this chasm which exists between their work and our work, is deplorable in the public interest. I have done my best to bring the truth home to my friends at the Ministry of Health and other places, and we are gradually finding a means of closer co-ordination. Until the two Services are pulling together and until the best brains of the two are brought together, you will not get the best for the people. This tonsil business is an example of the harm that may be done.

I thank you, Sir, for having allowed me to speak, and I think I have said all that may wisely be said.

The Chairman: It is not for me to join in the discussion, but in addition to the sort of danger by which operators are pushed into this operation by the cacoethes operandi, there are the ideas of the patients themselves. I saw an American patient and I said to him: "You have had your septum resected". "That is so." "What was that done for?" "Can't say: everyone was having theirs done, so I thought I'd better have mine done." And there was the lady who turned up in an obstetric physician's study. He said to her, "I'm sorry I've got to break it to you, but you will have to have amputation of the cervix done, and I shall have to take out one of your ovaries." "That doesn't frighten me at all, I have already had pan-hysterectomy done!" And I daresay you know about the American who was picked up unconscious in a London street. $\mathrm{He}$ was taken to a clinic, and when he was stripped they found, written across his abdomen in indelible ink, the words "Please do not operate on my appendix: it has already been removed three times." I hope I am not offending him, but 
there is a friend of mine here who is an oto-laryngologist. If I say he strikes me as a sort of poacher turned gamekeeper he may understand. I refer to Mr. T. B. Layton. I ask him to say a few words.

Mr. T. B. LAYTON, F.R.C.S.: It is very good of you to call upon me to speak, Sir.

I am entirely in agreement with the terms of this resolution, but I shall abstain from voting, because I do not think clinical medicine is a subject you can deal with in the same way as in a political debating society. Those who are removing too many tonsils will be benefited by the arguments put forward in favour of that, and they will be harmed by the remarks of the opposers of the motion, and no salutary influence will be obtained from a large show of hands. Such things always redound on the people who do them, sooner or later.

I would make various points with regard to this subject, points which, I think, tend to result in excessive operating.

First, we should get rid of the term "enlarged tonsils". With the rarest exceptions, we do not operate because tonsils are enlarged, we operate because they are a focus of sepsis, because they are infected. An enlarged tonsil may be an area of sepsis. I will quote the original idea of what an enlarged tonsil meant. Morel Mackenzie described an enlarged tonsil as " one which is the size of a walnut, frequently the size of a bantam's egg, sometines the size of a hen's egg". It is only once in about five years that I see tonsils of that size. Let us get rid of the term "enlarged tonsils", then we shall not have people removing tonsils which peep out beyond the anterior pillar because they have the implication of enlargement.

Next-and this is one of two things in regard to which I disagree with Lord Dawson-not exactly disagree, but I think he lays too much stress on it-is in regard to the sinuses. If for sinuses he will substitute the mucous membrane of the nasal fossa, or the naso-pharynx as a whole, I agree. I do not want the medical profession to cease doing one mechanical thing only to go to another series of mechanical instrumentations within the nose. I agree with Lord Dawson that you never can absolutely guarantee that the person will not have some limitation of the function of the palate. I have never been taught that by any laryngologist, but it has been impressed upon me by a certain number of singers whom I have examined.

I am also glad that Lord Dawson had something to say for the little bit of tonsil left behind. Much harm is done because the operator dare not leave behind a little bit of tonsil; he tries to remove all of it, and thereby endangers the life. And on that I disagree heartily with Dr. Dan McKenzie. Until today I never realised on how many points I differ from him. For him to say that this operation is devoid of risk is beyond my understanding; how a man with so much experience can say that! There is no operation in surgery which, in comparison with its magnitude, is fraught with so many disastrous complications and dangers, many of which are lethal.

Next with regard to so-called adenoid facies. There is no such thing as typical adenoid facies; I am surprised at Dr. McKenzie still putting it forward. It was first put forward by Sir Arbuthnot Lane and Mr. Lambert Lack. Neither French nor Americans have accepted it. Certain anatomists, led by Sir Arthur Keith, started to disprove it during the War years; and odontologists have taken it up 
and concluded that what the laryngologists have taught all these years was wrong. And recently there was a discussion at the Royal Society of Medicine at which laryngologists said there is no such thing.

Dr. LeOnard Findlay: My first duty is to thank you, Sir, for calling upon me to take part in this most interesting discussion.

Like Dr. Dan McKenzie, I must say that I am a little astonished at the mildness of the motion put forward by the openers of the debate this evening. If Dr. Glover, for instance, has any confidence in the statistics that he has shown us tonight, it seems to me that he can come to no other conclusion than that the tonsil, however diseased, is one of the greatest boons that a child can possess and therefore that its removal is really criminal. According to the figures quoted the removal of the tonsil has not only no curative action but indeed makes the child more susceptible to the greatest variety of diseases. This surely cannot be true. Of course, because a tonsil is removed, or adenoids are removed, it does not necessarily mean that the whole naso-pharynx cannot be infected, but that there can result a good-going tonsillitis after the tonsils have been removed is more than I can credit.

I know that in Glasgow the schools for the deaf child have gradually been becoming empty, in great part because severe otitis media was diminishing in frequency, and this change for the better has been coincident with the more frequent removal of the tonsils. Nor do we now see the amount of cervical adenitis that we did formerly. I admit that there are several factors which have played a part in this latter improvement but attention to the tonsils has certainly been one of them.

There has been much talk this evening about not removing the tonsils without adequate cause; but what is "adequate cause"? I should like to raise one aspect of the question which to me seems very important. If it is true that removal of the tonsils has diminished the incidence of otitis media with its consequent deafness and also cervical adenitis, this surely points to a definite prophylactic effect of the operation. In my experience also, tonsillectomy has a certain prophylactic effect in the rheumatic infection. In the examples of the rheumatic infection as a whole arthritis is a more frequent manifestation than chorea, whereas in those cases in which the infection has set in after tonsillectomy, chorea is more frequent than arthritis. Thus it would seem that tonsillectomy has a prophylactic effect in the case of rheumatic arthritis, and when we remember that carditis is more prone to follow on arthritis than on chorea this fact has an increased importance. Hence, from the point of view of prophyaxis of otitis media, cervical adenitis and rheumatic carditis, in any case in which there existed doubt regarding disease of the tonsil I should recommend that it be removed rather than left.

DR. KERSHAw (Health Department, Ealing): I would like an opportunity to refute the suggestion that we in the school medical service are of the "single track" mind. "It is perhaps better to progress steadily along a single track than stagnate in a mere siding. My second reason for rising is, that I am just completing a minor and unpretentious research into this problem, and though $\mathrm{I}$ have only some hundreds of cases as against thousands of some workers, the results I have obtained are of some use in assisting this meeting to arrive at a conclusion. I tried to approach the problem with two points in mind: (I) that an operation is redundant and unjustified if it is performed without adequate indication; (2) that 
adequate indication of operation is the presence of some symptom or harmful condition usually relieved by such operation. In this case I am omitting cosmetic considerations. I do not think that even under that heading you will exclude matters affecting the architectural beauty of the palate.

I approached the matter, first by investigating the after-histories of a number of cases of tonsillectomy. The field covered is a school population of a little over 10,000. I have not yet got the results as fully as I would like. There were $4 \mathrm{I} 6$ in whom tonsillectomy was performed in the last three years. I looked for a history of certain cardinal symptoms: colds, sore throats, mouth-breathing, certain ear affections, and rheumatism among them. As one would expect, a less frequent occurrence of sore throat is a not infrequent sequel of the operation. 85 per cent. of the cases were improved, 5 per cent. were not improved. Susceptibility to colds, and frequent colds, is part of the history of 353 of them. Improvement was obtained after operation in 84 per cent. of these; no improvement in I6 per cent. There was mouth-breathing in 250. This was improved in 75 per cent. of the cases operated upon, not improved in 25 per cent. I would point out that of 150 cases operated upon at the Borough clinic, 90 per cent. were improved from the point of view of mouth-breathing. Of Io6 cases operated upon privately and at hospitals 53 per cent. improved and 47 per cent. were unimproved. I am not putting this forward as a reason why people should go to the clinic; it is because cases dealt with at the clinic are followed up afterwards by nurses of the clinic, and after-care is insisted on and supervised.

Of ear affections, definite otorrhœa or frequent earache occurred in the history of 73 cases. 80 per cent. were improved, 20 per cent. not improved.

The results in the rheumatic cases were peculiar. The series is small; 200 cases of marked rheumatism were returned in the borough lists as abnormal children, and 96 of these were investigated. 43 of these had been operated upon; I4 had improved since the operation, 8 had not improved, and $2 \mathrm{I}$ had rheumatic trouble since the operation. In 53 such cases not operated upon, the tonsils appeared normal in 30, slightly enlarged in I9, definitely large, i.e., projecting beyond the posterior pillar, in 4 cases. Of the cases of less marked rheumatism which had not been included in the return of abnormal children, 65 had had their tonsils removed, 20 were improved after the operation, Io were unimproved, and 35 of them had only developed their rheumatic symptoms after the operation. The mischievous might suggest that in removing the tonsils the surgeon had removed the protection against rheumatism. Another possibility, and a more likely one, is that since these rheumatic symptoms usually only occur when the child was approaching the eighth year or later, the tonsils were removed before the child reached the age at which it would receive the "Rheumatism" label.

If tonsils were enlarged but there were no symptoms associated with them, the case was put down for observation. This occurred in 668 children who had had no symptoms referable to the throat for periods varying between one and six years previously. In the three age groups, under eight, between eight and eleven, and over eleven years, I noted that the percentage with invisible or very small tonsils rose with age, being II per cent., I6 per cent. and I8 per cent. More important, however, was the fact that only 21 per cent., I6 per cent. and II per cent. respectively had developed any of the symptoms usually associated with diseased tonsils. I would therefore suggest that the proper treatment for the large, symptomless tonsil is not prophylactic removal but observation at 
intervals of say six months with operation, as and when symptoms arise, a treatment which the School Medical Officer can well carry out.

Mr. E. D. D. DAvis: I merely came to listen and learn, and I congratulate those who opened the discussion on the very able way in which they have expressed themselves.

To Dr. Alison Glover a great tribute should be paid, because I think he has made a very definite attempt to find out why tonsils become diseased and why it is necessary to remove them. For the same reason I should have liked to have heard more about the function of the tonsil. It has the structure of a lymphatic gland, it behaves like one, and owing to its exposed position it is more liable to disease. That should be emphasised in the training of students. If they were taught that tonsillitis is primarily due to infection from one patient to another, and to drinking polluted food, milk, water, etc., and that it may be part of a general infection, and that when secondary tonsillitis exists it is due, often, to infection of the nose, and that one frequently sees it after a nasal operation which has gone septic, they will see the matter in a better light. You can see it occur after extraction of teeth when there is a septic mouth.

As to the cause and the prevalence of diseased tonsils, and the necessity for removing them, some of us have been carrying out for the Board of Education an investigation on this point. We are asked to go to the child welfare clinics and see these children from six months to five years of age and try to ascertain why they have infected tonsils, if they have. It has come to be a difficult problem, because there are so many contributory causes which are linked up with public health and housing. But we found that these children, at certain seasons, would have a tonsillitis, which was temporary and then it would disappear. As we got up to five years of age, then symptoms and signs necessitating removal of tonsils appeared in a certain percentage. I wish to thank Dr. Glover for the definite work he has done and the attempt he has made to investigate the cause of this trouble.

Mr. J. F. O'MALley: I agree with Mr. Layton that we must try to solve this problem, and that, whatever way the voting may go, it will help the problem forward. On one side you have the view of the person whose work is concerned with the ear, nose and throat; he is an individualist, and he is up against the problem of seeing whether the child is suffering from a disease in his line, to see if it is a disease which he can remove. His outlook must be different from that of the man who takes up the matter from the preventive medicine point of view; he approaches it from the statistical aspect. I should like, before leaving the point, to enter a protest against Lord Dawson's contempt for Nature's provision for the drainage of the accessory sinuses, because I regard that as one of the most perfect pieces of machinery for the purpose which could be conceived. Owing to our evolution, the sinuses have had to be somewhat cramped. The sinuses in the lower mammals and the chimpanzee are more open, but in man, when his face became reduced to the European angle, it was smaller, and the sinuses have to be fitted into that smaller space, and there are smaller openings in consequence. But in man, cold air does not enter the sinuses direct; it enters the nasal passages, and in the next inspiration it is withdrawn into the chest. With the next expiration some of the air coming out enters the sinus secondarily. It is capable of exerting a pressure up to $440 \mathrm{~m} . \mathrm{m}$. of water pressure, which is an extraordinary suction action for the sinuses. 
I have been very much interested in the statistical aspect. Last year Dr. Glover gave statistics at a Laryngological meeting which impressed me very much, and I read the paper with great care.

With regard to the relationship to otorrhœea, the conclusions Dr. Glover arrived at were at variance with my own experience and close observation for two years. He quoted Dr. Payton as having studied the incidence of otitis and found it was increased by the removal of adenoids.

(At this period of the evening the time limit for remarks had been reduced and Mr. O'Malley was not permitted to conclude.)

Mr. Herbert Tilley and Dr. Dan McKenzie here replied.

The Chalrman: I first ask if the majority of those present at this Meeting wish to vote at all. I read in "The Times" recently that Lord Banbury said that he had spent most of his life in stimulating discussion and preventing legislation, a very wise remark. The chairman of a meeting is supposed to be without bias, that is, a good chairman is. But we none of us can get rid of bias, and I can, personally, only think that a vote on a subject like this is most unscientific. I do not know whether it is a wave of democracy, which, fortunately, is rapidly dying out, but I can speak freely on the subject as I began life as an anarchist, and I am finishing as a quietist; and I ask myself what the vote would have been if Harvey, or Jenner, or Lister had had their researches voted on. I do not know that there has ever been a vote on appendicitis, which was created since my student days, for when I was a student I never saw such a case operated upon. And yet the question of appendicitis has helped itself to get itself as settled as anything can get settled in this world, without votes. Therefore, from the chair, I first ask for a show of hands as to whether, having heard this most interesting and stimulating debate-I feel that these debates make us recast our views-you wish the resolutions put to the meeting.

It was unanimously agreed that no vote be taken.

On the proposition of Lord Dawson of Penn, a hearty vote of thanks was accorded to the Chairman.

\section{THE HIPPOCRATIC TRADITION.}

By MatThew B. RAY, D.s.o., M.D. (Edin.)

\section{Part I.-Ancient Greek Medicine.}

Who was this great man, Hippocrates, this outstanding personality who well over twenty three centuries ago kindled a torch whose light still shines before men?

In order to understand how the great tradition associated with his name arose the imagination must be carried back to a time when the medical art was entirely in the hands of the priest and magician. It was only concerned with the propitiation of those deities who sent disease and death upon mankind in anger and revenge for impiety, vows unfulfilled and sacrifices unoffered.

These ancient divinities were evolved from the religious faith and practices of immigrant races from the North who personified potencies for good or evil as gods or dæmons. In process of time, the Greeks, aided by the imagination of their 